Abstracta Iranica Abstracta Iranica

Revue bibliographique pour le domaine irano-aryen

Volume 27 | 2006

Comptes rendus des publications de 2004

\title{
Central Asia and the Caucasus, Transnationalism and Diaspora. Londres - New York, Routledge, 2005, 235 p.
}

\section{Bayram Balci}

\section{(2) OpenEdition}

1 Journals

\section{Édition électronique}

URL : http://journals.openedition.org/abstractairanica/6084

DOI : 10.4000/abstractairanica.6084

ISSN : 1961-960X

Éditeur :

CNRS (UMR 7528 Mondes iraniens et indiens), Éditions de l'IFRI

\section{Édition imprimée}

Date de publication : 15 mai 2006

ISSN : 0240-8910

\section{Référence électronique}

Bayram Balci, «Central Asia and the Caucasus, Transnationalism and Diaspora. Londres - New York, Routledge, 2005, 235 p. », Abstracta Iranica [En ligne], Volume 27 | 2006, document 228, mis en ligne le 02 janvier 2007, consulté le 25 septembre 2020. URL : http://journals.openedition.org/ abstractairanica/6084; DOI : https://doi.org/10.4000/abstractairanica.6084

Ce document a été généré automatiquement le 25 septembre 2020.

Tous droits réservés 


\title{
Central Asia and the Caucasus, Transnationalism and Diaspora. Londres - New York, Routledge, 2005, 235 p.
}

\author{
Bayram Balci
}

L'espace et les sociétés post-soviétiques constituent des laboratoires d'observation privilégiés pour toutes sortes de phénomènes diasporiques, ainsi que pour les manifestations identitaires véhiculées par ces phénomènes. Les auteurs de cet ouvrage collectif, tous spécialistes du Caucase et de l'Asie Centrale, en étudient les évolutions à travers le temps et les soubresauts les plus récents. La somme des contributions rappelle qu'aux exodes engendrés par la conquête russe ont succédé des migrations de masse plus ou moins forcées par les Bolcheviks dans les années 1920 puis, dans les deux décennies qui suivirent, la déportation de populations entières. Ces réfugiés, déportés, exilés forment aujourd'hui des communautés diasporiques diverses, nourrissant de leurs spécificités le débat actuel sur les diasporas. Tous répondent au moins à la définition la plus généralement admise du phénomène - à savoir celle de Walker Connor, lequel en fait « le segment d'un peuple vivant à l'extérieur des frontières de la patrie ». Mais cela ne suffit pas. L'intérêt ici des analyses réside dans les perceptions et notions d'identité nationale et surtout dans les actions et manifestations plus ou moins militantes de ces anciens et nouveaux nationalismes. Car il s'agit ici d'aborder la manière dont les «nationalités » ont été créées par les Bolcheviks et les Soviets par la partition soigneusement orchestrée de ces régions visant à affaiblir les solidarités, par la fixation de langues distinctes pour chaque nation titulaire, par la sédentarisation forcée des nomades et la collectivisation. Comme nous le montrent ici les auteurs, la greffe a pris au delà des espérances de ses concepteurs initiaux, puisqu'au détriment de l'identité idéologique de l'homo sovieticus. Les diasporas endossèrent également ces nouvelles identités, sans pourtant les avoir expérimentées en participant à la mythification et à l'idéalisation de la patrie réelle ou putative, alimentant la mémoire collective d'un nouveau trans-nationalisme ethnique. Certaines de ces diasporas, 
présentées dans cet ouvrage, sont effectivement engagées dans du lobbying international pour venir en aide au pays d'origine pour sa défense, sa sécurité, sa rénovation et son essor, œuvrant en ce sens pour la consolidation de ce transnationalisme. L'ouvrage est composé d'une dizaine de chapitres de longueur inégale. Au chapitre théorique de Jolle Demmers, « Nationalism form Without: Theorizing the Role of Diasporas in Contemporary Conflict" succède celui, plus empirique, de Shirin Akiner, qui tente d'établir une typologie des diasporas au Kazakhstan. Viennent ensuite d'autres études de cas, sur les Russes en Asie Centrale, les cas azéris et arméniens expatriés, puis les communautés afghanes en Ouzbékistan, études menées respectivement par Kulbushan Warikoo, Stephan Astourian et Natylay Khan. L'ouvrage traite également du cas particulier des Ouïghours d'Asie centrale (Ablet Kamalov), de l'islam en Chine (Dru Gladney) et des Assyriens dispersés (Eden Naby). L'ouvrage est agréable à lire, grâce à des tableaux précis qui rendent le texte plus explicite. La présence d'un index des noms propres contribue à la maniabilité de l'ensemble.

INDEX

Thèmes : 4.6. Histoire de l'Asie centrale et Caucase (à partir de 1917)

\section{AUTEURS \\ BAYRAM BALCI}

IFEAC - Tachkent 